\title{
Pregnancy outcomes and associated factors for uterine rupture: an 8 years population-based retrospective study
}

\author{
Sheng Wan ${ }^{1 \dagger}$, Mengnan Yang ${ }^{1 \dagger}$, Jindan Pei ${ }^{1}$, Xiaobo Zhao ${ }^{1}$, Chenchen Zhou', Yuelin Wu', Qianqian Sun', \\ Guizhu Wu ${ }^{2^{*}}$ and Xiaolin Hua ${ }^{1 *}$ (B)
}

\begin{abstract}
Background: Uterine rupture is an obstetrical emergency with serious undesired complications for laboring mothers resulting in fatal maternal and neonatal outcomes. The aim of this study was to assess the incidence of uterine rupture, its association with previous uterine surgery and vaginal birth after caesarean section (VBAC), and the maternal and perinatal implications.
\end{abstract}

Methods: This is a population-based retrospective study. All pregnant women treated for ruptured uterus in one center between 2013 and 2020 were included. Their information retrieved from the medical records department were reviewed retrospectively.

Results: A total of 209,112 deliveries were included and 41 cases of uterine rupture were identified. The incidence of uterine rupture was 1.96/10000 births. Among the 41 cases, 16 (39.0\%) had maternal and fetal complications. There were no maternal deaths secondary to uterine rupture, while perinatal fatality related to uterine rupture was $7.3 \%$. Among all cases, 38 (92.7\%) were scarred uterus and 3 (7.3\%) were unscarred uterus. The most common cause of uterine rupture was previous cesarean section, while cases with a history of laparoscopic myomectomy were more likely to have serious adverse outcomes, such as fetal death. 24 (59.0\%) of the ruptures occurred in anterior lower uterine segment. Changes in Fetal heart rate monitoring were the most reliable signs for rupture.

Conclusions: Incidence of uterine rupture in the study area, Shanghai, China was consistent with developed countries. Further improvements in obstetric care and enhanced collaboration with referring health facilities were needed to ensure maternal and perinatal safety.

Keywords: Uterine rupture, Cesarean section, VBAC, Maternal and neonatal outcome, Risk factors

*Correspondence: wugz6666@126.com; xiaolin_hua@tongji.edu.cn tSheng Wan and Mengnan Yang contributed equally to this work. ${ }^{1}$ Department of Obstetrics, Shanghai First Maternity and infant hospital, Shanghai Tongji University School of Medicine, 2699 West Gaoke Road, Shanghai 201204, China

2 Department of Gynecology, Shanghai First Maternity and infant hospital, Shanghai Tongji University School of Medicine, 2699 West Gaoke Road, Shanghai 201204, China

\section{Background}

Uterine rupture (UR) is a full-thickness separation of the uterine wall through breaching during pregnancy, labor, or immediately after delivery [1-3]. According to the world health organization, the average incidence of UR is 5.3/10 000 [1]. UR is one of the most dangerous obstetric problems and a life-threatening emergency. It is an important cause of maternal and perinatal morbidity and mortality [4-6]. Maternal mortality ranges between 1 and 13\% and neonatal mortality between 74 and 92\%

(c) The Author(s) 2022. Open Access This article is licensed under a Creative Commons Attribution 4.0 International License, which permits use, sharing, adaptation, distribution and reproduction in any medium or format, as long as you give appropriate credit to the original author(s) and the source, provide a link to the Creative Commons licence, and indicate if changes were made. The images or other third party material in this article are included in the article's Creative Commons licence, unless indicated otherwise in a credit line to the material. If material is not included in the article's Creative Commons licence and your intended use is not permitted by statutory regulation or exceeds the permitted use, you will need to obtain permission directly from the copyright holder. To view a copy of this licence, visit http://creativecommons.org/licenses/by/4.0/. The Creative Commons Public Domain Dedication waiver (http://creativeco mmons.org/publicdomain/zero/1.0/) applies to the data made available in this article, unless otherwise stated in a credit line to the data. 
as a result of UR [1]. The determinant factors for maternal and fetal outcomes of UR differ across geographical regions due to differences in socio-demographic status, the availability and accessibility of routine obstetric care, and health system effectiveness. Analyzing outcomes and factors associated with maternal and fetal complications of UR in the study area, Shanghai, is important to prevent and improve local clinical management by designing appropriate policies and strategies.

Although the occurrence of UR is relatively rare in general, it is more frequent in low-income compared to highincome countries $[7,8]$. In high-income countries, the greatest risk factor is a scarred uterus, typically from a previous cesarean delivery. Risks of UR are also related to other factors, such as parity, obstructed labor, induction of labor, use of prostaglandins, and/or breech presentation $[1,7,9]$. VBAC (vaginal birth after caesarean section) is an important practice to reduce caesarean section rate. However, in China, many hospitals are reluctant to attempt a TOLAC (trial of labor after caesarean delivery) due to increased risks of severe adverse outcomes, such as UR and fetal or neonatal death. Nevertheless, reports on UR and its maternal and perinatal outcomes for such delivery are lacking in China. As to scarred uterus, previous studies on the outcomes of UR were generally concentrated on patients with previous cesarean section, while very few studied patients with other gynecological surgery history.

The aim of this study was to analyze all cases of UR in our hospital during the period 2013-2020 to assess the incidence, its linkage with previous caesarean and other gynecological surgery history, and the maternal and perinatal risk factors as well as the implications of UR.

\section{Methods}

\section{Study design and participants}

A retrospective analysis was conducted using UR cases recorded at the Shanghai First Maternity and Infant Hospital, Tongji University School of Medicine from June 1, 2013 to December 31, 2020. This hospital is a tertiary referral center for critical and severe diseases of pregnant and delivery women and has the largest number of deliveries in the Eastern China region. This study was approved by the Ethics Review Committee of Shanghai First Maternity and Infant Hospital, Tongji University School of Medicine (KS20268). We excluded cases that were pregnancies before 20 weeks or experienced traumatic of motor vehicle accidents.

\section{Variables of the study}

Patients with UR were divided into two groups according to maternal and/or fetal complications or not. A comparison between the two groups were conducted.
Maternal complication was defined as the postpartum hemorrhage (a cumulative blood loss of greater than or equal to $1000 \mathrm{~mL}$ or blood loss accompanied by signs or symptoms of hypovolemia $24 \mathrm{~h}$ post birth) [10], hysterectomy, obstetric injury (genital and/or urinary injury), and maternal death. Neonatal complication was defined as Apgar score $<7$ at $5 \mathrm{~min}$, neonatal intensive-care unit (NICU) admission, and neonatal death [11, 12]. A complete UR was defined as tearing in all layers of the uterine wall, including the serosa and amniotic membranes. An incomplete UR was defined as tearing in the muscular layers, with intact serosa or amniotic membranes [13].

We retrieved the charts of UR cases and collected four independent variables: 1) socio-demographic characteristics, including age, parity, education, and place of residence; 2) pregnancy and labor related variables, such as previous cesarean section, ectopic pregnancy, uterine myomectomy and other uterine operation history, and intrauterine operation; 3) clinical symptoms and signs; and 4) maternal and fetal outcomes (delivery method, blood loss and transfusion, postpartum hemorrhage, ICU, birth weight, 5-min Apgar score <7).

\section{Data processing and analysis}

All collected data were rechecked for completeness and coded. Then the data were entered and processed using Epidata 3.1 software. Data are expressed as mean \pm standard deviation, or median (25th-75th percentile). The normality of variables was assessed. Differences between the two groups were compared with the Student's t-test and the Mann-Whitney U test for continuous variables: mean and median, respectively, and with the $\chi^{2}$ test or Fisher's exact test for categorical variables. We used the Spearman coefficient to assess the correlation between UR rate and VBAC rate. Multivariable logistic regression analysis was performed to examine the association of included variables with UR. Odds ratios (OR) were presented with $95 \%$ confidence intervals (CI). Statistical analyses were performed using SPSS software, version 22.0 (SPSS Inc., Chicago, IL, USA). A $p$ value of less than 0.05 was considered statistically significant.

\section{Results}

During the study period, 41 UR were identified among a total of 209,112 deliveries. The incidence of UR was $1.96 / 10000$ births. There were no maternal deaths, hysterectomy, or obstetric injury secondary to UR found in our study. Among all cases, there were 16(39.0\%) cases with complication and 25(61.0\%) cases without; 15 (36.6\%) were complete rupture cases and 26 (63.4\%) were incomplete rupture cases; $38(92.7 \%)$ were scarred uterus and $3(7.3 \%)$ were unscarred uterus. 
The total number of deliveries and the rates of scarred uterus and VBAC increased over the eight years. However, the proportion of UR remained consistent (Fig. 1). UR rate was not associated with VBAC rate (correlation coefficient: $-0.095, p=0.826$ ).

Demographic data and clinical characteristics of mothers and fetuses between UR and non-UR were presented in Table 1. Patients in UR group were significantly older and more than half (58.5\%) of them were over 35 years old, compared to the $18.8 \%$ of the non-UR group. The mean gravidity of the case women of the UR group was $2.95 \pm 1.41$, significantly higher than that of the non-UR group $(1.85 \pm 1.09)$. The proportion of primiparity in non-UR group $(72.7 \%)$ were significantly higher than UR group (24.4\%). There was a statistically significant difference in the gestational age at delivery $(39.0 \pm 1.6$ vs. $37.0 \pm 3.5)$, birth weight $(3296.9 \pm 470.1$ vs. $3016.6 \pm 755.1)$ and maternal hospital stay $(4.3 \pm 4.1$ vs $7.7 \pm 5.3)$ between the groups $(p<0.05)$. Compared to the non-UR group, the proportion of gestational hypertension $(7.3 \%$ vs. $1.1 \%)$, artificial reproductive technology ( $12.2 \%$ vs. $4.0 \%)$, cesarean delivery ( $100.0 \%$ vs $39.9 \%)$, postpartum hemorrhage ( $31.7 \%$ vs. $1.5 \%$ ), preterm birth (39.0\% vs. 6.6\%), and 5-min Apgar score $<7$ (19.5\% vs. $1.0 \%)$ were significantly higher in the UR group $(p<0.05)$.

Table 2 displayed the occurrence of obstetrical risk factors in complicated or not complicated UR groups. Among all patients with UR, 16 (39.0\%) had maternal and fetal complications. Postpartum hemorrhage was the main maternal complication and most blood loss occurred during the surgery. 13 cases had blood loss above $1000 \mathrm{ml}$. Among them, five had excessive blood loss above $2000 \mathrm{ml}$. As to fetal complications, we had 8 cases of Apgar score $<7$ at $5 \mathrm{~min}, 5$ cases of NICU admission, and 3 cases of neonatal death. Compared with not complicated UR, women in complicated UR group had higher proportions of primiparity, uterine myomectomy history, artificial reproductive technology use, blood transfusion, intensive care unit (ICU) admission, and complete UR. Complicated UR group also presented a longer hospital stay, a higher probability of preterm birth, multiple pregnancy, a smaller rupture gestational weeks, a lower birth weight, and prevalence of previous cesarean history.

Patients' rate of abnormal fetal heart rate $(68.8 \%$ vs. $24.0 \%$ ) and vaginal bleeding ( $43.8 \%$ vs. $24.0 \%)$ were significantly higher in the UR group with maternal and fetal complications. Among all 16 cases of complicated UR, eight cases presented signs and symptoms during pregnancy, five cases with the onset of labor and three cases during the process of labor. In the complicated group, the range of ruptured gestational week was 23 to 40 weeks. In the not complicated group, the earliest and the latest ruptured gestational week were 35 weeks and 40 weeks respectively. No maternal death was observed. The perinatal fatality attributable to UR

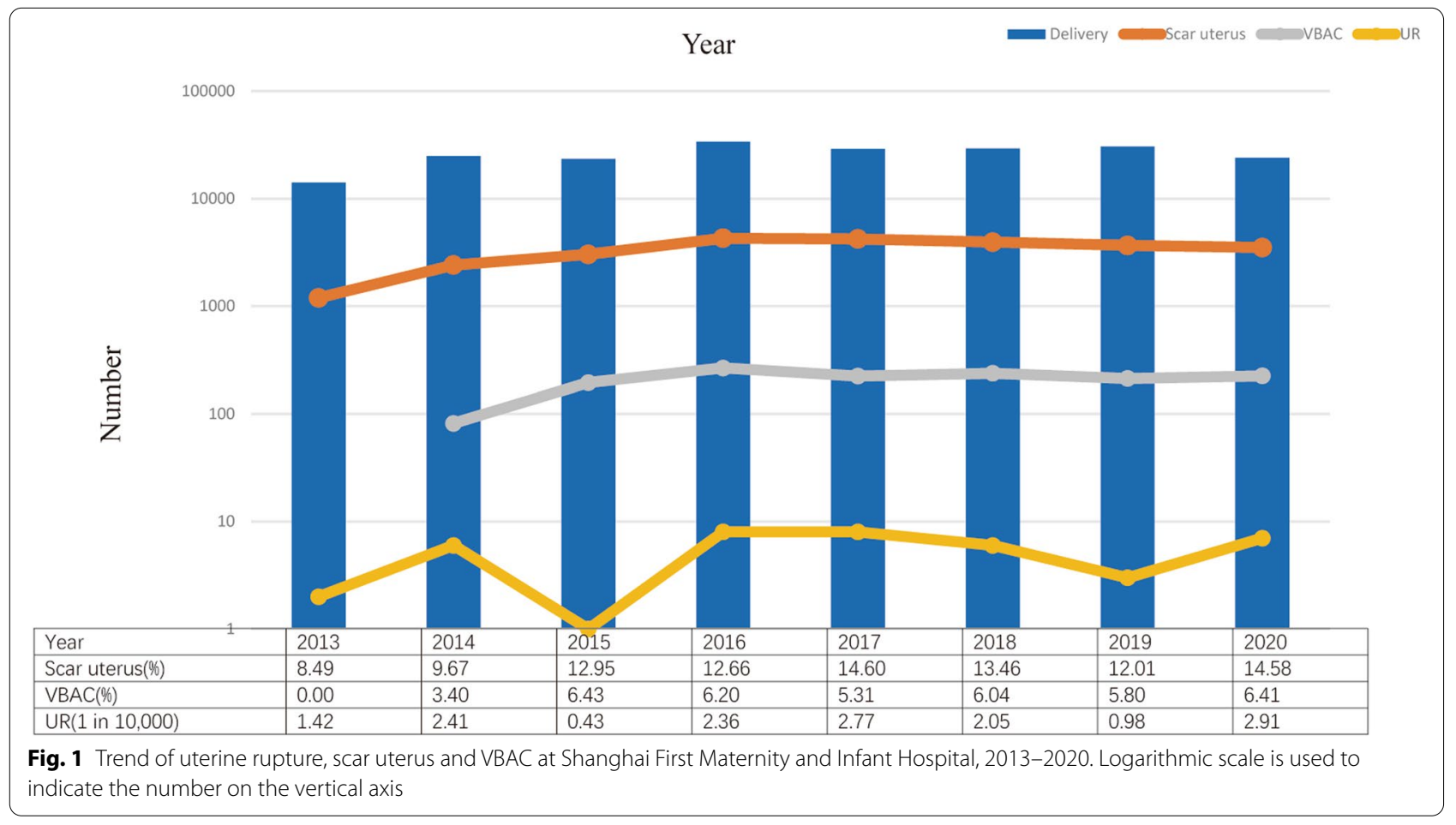


Table 1 Characteristics of mothers and newborns in study

\begin{tabular}{llll}
\hline & Non-UR & UR & $p$ value \\
\hline Mothers & & & $<0.001^{*}$ \\
Age (years) & $30.9 \pm 4.0$ & $35 \pm 3.78$ & $<0.001^{*}$ \\
$>35 y$ & $39,313[18.8]$ & $24[58.5]$ & $<0.001^{*}$ \\
Gravidity & $1.85 \pm 1.09$ & $2.95 \pm 1.413$ & $<0.001^{*}$ \\
Primiparity & $152,024[72.7]$ & $10[24.4]$ & 0.605 \\
Gestational diabetes mellitus & $22,793[10.9]$ & $6[14.6]$ & $0.002^{*}$ \\
Gestational hypertension & $2300[1.1]$ & $3[7.3]$ & $0.023^{*}$ \\
Artificial reproductive technology & $8365[4.0]$ & $5[12.2]$ & $<.001^{*}$ \\
Hospital stay & $4.30 \pm 4.10$ & $7.71 \pm 5.28$ & $<0.001^{*}$ \\
Postpartum hemorrhage & $3137[1.5]$ & $13[31.7]$ & \\
Deliveries/Newborns & & $41[100]$ & $<0.001^{*}$ \\
Cesarean delivery & $83,436[39.9]$ & $37.04 \pm 3.52$ & $0.001^{*}$ \\
Gestational age (weeks) & $39.00 \pm 1.60$ & $16[39.0]$ & $<0.001^{*}$ \\
Preterm birth (<37 weeks) & $13,801[6.6]$ & $3016.59 \pm 755.1$ & $0.022^{*}$ \\
Birth weight (g) & $3296.9 \pm 470.1$ & $1[2.4]$ & 0.639 \\
Macrosomia & $11,083[5.3]$ & $8[19.5]$ & $<0.001^{*}$ \\
5 min Apgar $<7$ & $2091[1.0]$ & & \\
\hline
\end{tabular}

${ }^{*} p<0.05$, values are expressed as mean \pm standard deviation or number [percentage]

UR Uterine rupture

was 7.3\%. 21 (51.2\%) mothers were diagnosed with UR preoperatively and $20(48.8 \%)$ were diagnosed intraoperatively. The diagnosed time and the proportion of TOLAC were similar in the 2 groups $(p=0.156)$.

Multiple logistic regression analyses were employed to examine whether signs and symptoms were associated with the presence of UR with complication (Table 3). The model, which included all signs and symptoms as independent variables, showed that the abnormal fetal heart rate emerged as a significant and independent factor associated with the complicated UR compared with other signs. (OR $=12.45$; 95\% CI: $1.16-133.54 ; p<0.05)$. Other clinical signs were not statistically different. All three cases of neonatal deaths presented abdominal pain while two of them presented abnormal fetal heart rate at the same time. We also showed their detailed descriptions in Supplementary Table 1.

Figure 2 shows the rupture sites involved. 24 (58.5\%) cases were anterior lower uterine segment; 3 (7.3\%) cases had posterior segment rupture; $9(22.0 \%)$ cases were ruptured at the lateral segment; and 4 (9.8\%) cases were fundal segment rupture and one ruptured more than one place $(2.4 \%)$.

Detailed clinical information on all UR cases following laparoscopic myomectomy is shown in Table 4.

\section{Discussion}

UR in pregnancy is rare, but when it occurs the consequences can be life-threatening to both the mother and the fetus $[14,15]$. The occurrence of UR varies in different parts of the world. Globally, the incidence of UR is $0.07 \%$ with the tendency of being lower in the developed countries than the developing countries $[1,16]$. The rate of UR in our study was $0.0196 \%$, consistent with the rate observed in the developed countries as Shanghai is among the most economically developed regions in China, which is close to developed countries. There were no cases of maternal death due to UR in our study.

There has been a wide variation in the aetiology UR over years [17-19], where the increase rate of TOLAC and the use of uterotonics have created the two most common predisposing factors in the developed countries $[9,16,20,21]$. However, the major causes of UR in the developing countries are both obstetric and non-obstetric multitude of factors: multi-gravidity, teen-age pregnancy, old primi, poor socio-economic status, previous cesarean section scar, unsupervised labor, and unwise use of uterotonic agents [4].

Our study showed that the key risk factor of UR was the presence of scar, and previous cesarean section is the most important cause of uterine scarring. Therefore, to reduce UR rate, we need to strictly control the indication of cesarean section so as to reduce the rate of cesarean section. Globally, cesarean delivery rates have been steadily increasing over the past 20 to 30 years [22-24]. A major contributor to this has been elective repeat cesarean sections. Approximately one-third to half of the elective cesareans are performed because of a history of cesarean delivery $[22,25,26]$. Routine elective repeat cesarean section for all women with a prior 
Table 2 Characteristics of mothers and newborns in complicated and not complicated uterine rupture

\begin{tabular}{|c|c|c|c|}
\hline & $\begin{array}{l}\text { Complicated } \\
16\end{array}$ & $\begin{array}{l}\text { Not complicated } \\
25\end{array}$ & $\begin{array}{l}p \text { value } \\
/\end{array}$ \\
\hline \multicolumn{4}{|l|}{ Mothers } \\
\hline Age (years) & $35.77 \pm 4.38$ & $34.56 \pm 3.64$ & 0.357 \\
\hline$>35 y$ & $10[62.5]$ & $14[56]$ & 0.680 \\
\hline Gravidity & $3(1.5-4)$ & $3(2-3.5)$ & 0.517 \\
\hline Primiparity & $8[50]$ & $2[8]$ & $0.002^{*}$ \\
\hline Intrauterine operation & $10[62.5]$ & $12[48]$ & 0.364 \\
\hline Gestational diabetes mellitus & $2[12.5]$ & $4[16]$ & 0.757 \\
\hline Gestational hypertension & $3[18.75]$ & $0[0]$ & 0.053 \\
\hline Artificial reproductive technology & $4[25]$ & $1[4]$ & $0.045^{*}$ \\
\hline Scarred uterus & $13[81.25]$ & $25[100]$ & 0.053 \\
\hline Previous cesarean & $6[37.5]$ & $22[88]$ & $0.001^{*}$ \\
\hline Previous UM & $5[31.25]$ & $1[4]$ & $0.016^{*}$ \\
\hline Previous cornual pregnancy & $3[18.75]$ & $2[8]$ & 0.305 \\
\hline TOLAC & $2[12.5]$ & $8[32]$ & 0.156 \\
\hline Rupture of GA & $36.14(30.86-37.86)$ & $38.71(37.43-39.79)$ & $0.001^{*}$ \\
\hline Interval since last operation (years) & $4(2.5-6.5)$ & $4(3-6.5)$ & 0.584 \\
\hline Diagnosed in surgery & $10[62.5]$ & $10[40]$ & 0.16 \\
\hline Transfusion & $8[50]$ & $1[4]$ & $0.001^{*}$ \\
\hline Intensive care unit & $11[68.75]$ & $1[4]$ & $<0.001^{*}$ \\
\hline Hospital stay (days) & $7(5-10.5)$ & $5(4-7)$ & $0.043^{*}$ \\
\hline Abnormal fetal heart rate & $11[68.75]$ & $6[24]$ & $0.005^{*}$ \\
\hline Vaginal bleeding & $7[43.75]$ & $6[24]$ & $0.007^{*}$ \\
\hline Abdominal pain & $11[68.75]$ & $12[48]$ & 0.192 \\
\hline Other symptoms & $0[0]$ & $5[20]$ & 0.137 \\
\hline Emergency indication & $13[81.25]$ & $14[56]$ & 0.096 \\
\hline Complete UR & $9[56.25]$ & $6[24]$ & $0.036^{*}$ \\
\hline \multicolumn{4}{|l|}{ Deliveries/Newborns } \\
\hline Preterm birth (<37 weeks) & $10[62.5]$ & $6[24]$ & $0.014^{*}$ \\
\hline Twins & $4[25]$ & $0[0]$ & $0.018^{*}$ \\
\hline Birth weight (g) & $2970(1740-3500)$ & $3200(2945-3635)$ & $0.040^{*}$ \\
\hline
\end{tabular}

${ }^{*} p<0.05$, values are expressed as mean \pm standard deviation, number [percentage], or median (Q1-Q3)

UM uterine myomectomy, TOLAC trial of labour after caesarean delivery, GA gestational age, UR uterine rupture, NICU neonatal intensive care unit

Table 3 Signs and symptoms of rupture uterus presented in a multi-variable analysis

\begin{tabular}{lllll}
\hline & OR & $\mathbf{9 5 \% C l}$ & & p value \\
\hline Abnormal fetal heart rate & 12.446 & 1.16 & 133.54 & $0.037^{*}$ \\
Vaginal bleeding & 0.807 & 0.055 & 11.932 & 0.876 \\
Abdominal pain & 2.062 & 0.356 & 2.062 & 0.419 \\
Other symptoms & 0 & 0 & $/$ & 0.999
\end{tabular}

${ }^{*} p<0.05$, OR odd risk, $\mathrm{Cl}$ Confidence intervals

cesarean section is not universally advocated, desired, or without risk. Furthermore, multiple cesarean sections also carry the increased risks of placenta previa and placenta accrete with future pregnancies [27]. Such a policy would result in significant financial cost [28]. On the other hand, VBAC is able to resolve such problems. As another mode of birth after caesarean section, VBAC is associated with fewer complications, such as shorter maternal hospitalization, less blood loss, and a decreased incidence of puerperal infections and thrombotic events [29]. TOLAC is a safe option for most people and $75 \%$ women may be successful [30]. In recent years, VBAC has been supported as a way to decrease related complications and slow the increase in cesarean births to some extents. For instance, in Norway, all mothers with a previous caesarean section are offered a chance of TOLAC unless there is an absolute contraindication. As a result, the TOLAC rate is as high as 51 , and $80 \%$ succeed in that country [31]. While VBAC 


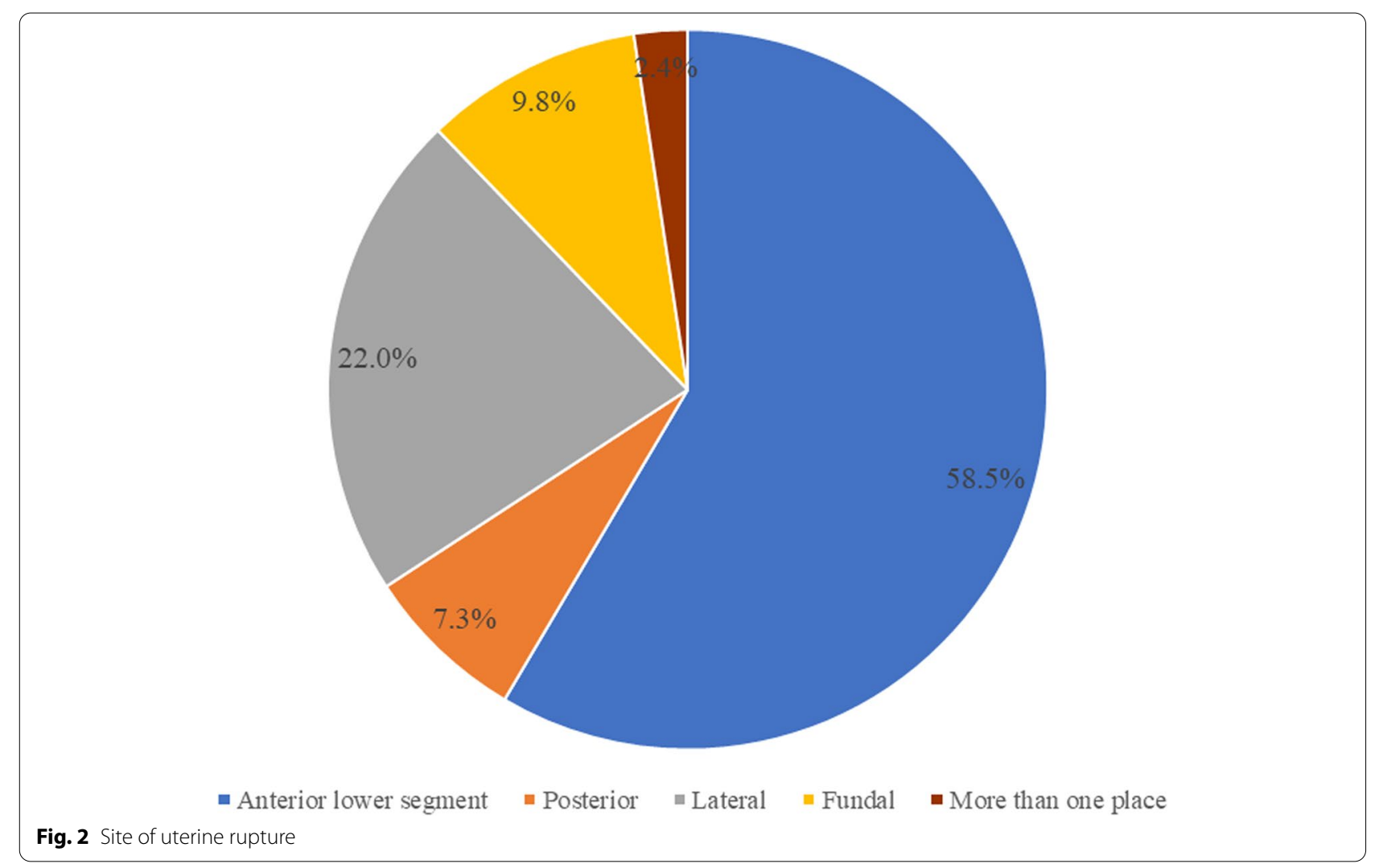

Table 4 Detailed surgical findings and obstetric outcomes of the six cases with uterine rupture following laparoscopic myomectomy

\begin{tabular}{|c|c|c|c|c|c|c|}
\hline Patient & 1 & 2 & 3 & 4 & 5 & 6 \\
\hline Age(yr) & 30 & 39 & 44 & 33 & 37 & 32 \\
\hline Year of surgery & 2014 & 2007 & 2013 & 2015 & 2018 & 2016 \\
\hline Number of myoma removed & 5 & 1 & 2 & 2 & 2 & 2 \\
\hline Myoma type & IM & IM & IM, SS & IM & $\mathrm{IM}, \mathrm{SS}$ & IM \\
\hline Myoma size(cm) & $6,3^{*} 4$ & 6 & $5,1.5$ & $3 * 2$ & 6,1 & 6,2 \\
\hline Uterine incision & MP & MP & MP & MP & MP & MP \\
\hline Cavity entered & No & No & No & No & No & No \\
\hline Hemostasis type & $\mathrm{BP}, \mathrm{S}$ & $B P, S$ & $B P, S$ & $\mathrm{BP}, \mathrm{S}$ & $\mathrm{BP}, \mathrm{S}$ & $B P, S$ \\
\hline Stitches & 3 Layers & 2 Layers & 2 Layers & 2 Layers & 2 Layers & 2 Layers \\
\hline Anti-adhesion agents & No & No & No & $\mathrm{DM}$ & $\mathrm{DM}$ & Yes \\
\hline Interval from surgery to pregnancy(yr) & 2 & 9 & 5 & 3 & 2 & 4 \\
\hline Gestational week of rupture & 31.43 & 36.43 & 37.43 & 30.29 & 23 & 35.43 \\
\hline Labor & No & No & No & No & No & No \\
\hline Volume of bleeding $(\mathrm{ml})$ & 3250 & 800 & 2000 & 2500 & 2850 & 1250 \\
\hline Number of fetuses & 1 & 1 & 1 & 1 & 1 & 1 \\
\hline Fetal survival & No & Yes & Yes & No & No & Yes \\
\hline Maternal survival & Yes & Yes & Yes & Yes & Yes & Yes \\
\hline
\end{tabular}


is being advocated by more and more countries, the VBAC rate in China was only $9.6 \%$ in 2016 , compared to $12.4 \%$ in the United States in the same year [32,33]. While TOLAC is an accepted practice in hospitals with advanced medical equipment and obstetric skills, it still can be controversial. A successful VBAC is associated with fewer complications compared with elective repeat cesarean delivery, whereas a failed TOLAC is associated with more complications [34]. TOLAC has gone through three stages in the U.S. Stage one, the VBAC rate had increased from 5\% in 1985 to $28.3 \%$ by 1996 as recommendations favored TOLAC; Stage two, the VBAC rate had decreased to $8.5 \%$ by 2006 as the number of UR and other complications related to TOLAC increased. During that time, some hospitals stopped offering TOLAC altogether; Stage three, VBACs had been on the rise again since 2016 and increased to $13.3 \%$ by 2018 , when a balance between TOLAC and safety was reached [33, 34]. The U.S. experience is worth learning and most part of China is currently going through the stage two, so we can see the reversal of the VBAC. Therefore, promoting TOLAC in China and ensuring safety is needed. In our study, we were expecting UR rates to become higher as more people attempted a TOLAC. However, this was not the case observed from this study and ruptures occurring after TOLAC did not become more serious. The ACOG (American College of Obstetricians and Gynecologists) recommended TOLAC depending on the hospital's resources and availability of obstetric, pediatric, anesthesiology, and operating room staffs [34]. Our hospital is one of the three hospitals with the largest number of births in China, and Shanghai is among the top medical treatment areas in China, which is close to developed countries. Therefore, we have rich enough medical experience to reduce the occurrence of UR and ensure the maternal and perinatal safety. Our study provides evidence that under the condition of strict control and indication, TOLAC is safe and reliable and worth carrying out. With the implementation of birth encouragement policy in China, an increasing amount of second-child pregnant women are choosing to attempt a TOLAC. As a result, the rate of cesarean section and the consequent risks of UR will decline as a whole, and the national medical burden and financial expenditure can be reduced.

The other two causes of uterine scarring identified in our study are previous myomectomy and previous cornual pregnancy. All cases with a previous myomectomy surgery were performed by laparoscopy. With the rise of minimally invasive techniques, laparoscopic surgeries are being performed in greater numbers today than ever before. Despite the overwhelming evidence that laparoscopic myomectomy is minimally invasive and associated with fewer perioperative complications, there is one question that is still under debate - does laparoscopic myomectomy increase the risk of subsequent UR? While some previous studies showed that there was no difference between laparoscopic and open myomectomy on the risk of UR, others demonstrated that laparoscopic procedure increased UR risk compared to open approach because it was believed to result in incompletely repaired muscle defects [35-38]. The use of powered instruments, limited instrumentation use, and the impossibility of palpation might be the reasons. Some techniques including multi-layer closure of the myometrium and limited use of electrosurgical energy should be adhered to by surgeons to decrease the risk [38]. In our study, it seems to lead to more serious outcomes regarding the six UR cases following laparoscopic myomectomy. Among them, four had excessive blood loss above $2000 \mathrm{ml}$ and presented signs of hemorrhagic shock, three of which had the worst outcome, i.e., the fetuses did not survive. The patients might even be influenced by long-term sequelae, which can adversely affect subsequent pregnancies. The removed myoma size and number in UR patients were within the average range of normal cases of laparoscopic myomectomy, which is consistent with other studies $[38,39]$. In addition, there is no evidence that indicates the appropriate length of contraception period needed after myomectomy to avoid UR. Currently this interval varies by facility [35]. Some suggested that 12 months might be adequate while others concluded there was no safe interval $[35,39,40]$. In our study, the only UR case without serious complication after laparoscopic myomectomy had an interval of nine years, which is the longest among the six cases. This finding indicates that keeping the duration of the contraception period longer will be safer for patients with a history of laparoscopic myomectomy. Therefore, clinicians must remain vigilant, particularly when the patients have a history of laparoscopic myomectomy. Regardless of the cause of scar uterus, special monitoring is needed during pregnancy and childbirth to ensure the health of the mother and the newborn.

In contrast to UR in women attempting TOLAC, the UR in women with unscarred uteruses occurs often completely unexpectedly. We found an incidence of UR among women who did not have previous uterine scar was $3 / 209112$ deliveries, which was in agreement of the incidence found by Thisted et al. using data from the Danish Medical Birth Registry [21]. All three UR cases in our study that were uncompleted UR found during the cesarean section with almost the same maternal and fetal complications rates as scarred uterus. Among them, two $(2 / 3)$ were multiple pregnancies with uterus contraction 
before the cesarean section, and one fell to birth vaginally because of obstructed labor. Our findings suggested that multiple pregnancies and obstructed labor are two major risk factors for UR in patients without a history of previous uterus surgery, which is in line with the recent reports published by Gibbins et al., Vandenberghe et al. and Vilchez et al. [41-43].

Timely detection of UR is conducive to improving maternal and infant outcomes. Symptoms are the only indicators that change dynamically, which can provide the first-hand information for the doctors. In the past, caregivers were taught to look for classic signs such as sudden tearing uterine pain, vaginal hemorrhage, cessation of uterine contractions, Bandl's ring, and regression of the fetus $[44,45]$. However, some studies have shown that these signs are not specific and are often absent [44, 46]. Our study shows that the change of the fetal heart rate is the most reliable presenting clinical symptom. Most of the cases also presented with abnormal pain and vaginal bleeding. Alertness to these signs is the key to the timely rescue and successful management. Other studies had the same conclusions consistent with ours $[44,46]$.

The most common site of rupture was in the lower uterine segment (58.5\%) in our study, which was the scar site of the previous cesarean section. This result is consistent with the findings of the study done by Rizwan et al. [4], in which $80 \%$ of the rupture was observed in the lower uterine segment.

Our study has several strengths: (1) a populationbased single-centered study, (2) covering a long period of time between 2013 and 2020 with a large sample size, (3) because all patients were delivered in a medical institution, we have a complete and systematic review of all medical records. All patients were followed up six weeks after delivery and no serious complications were found after discharge. However, the study is limited to Shanghai subjects and has limitations owing to the retrospective design. It only represents the level of developed regions in China. The situation in other parts of china is still unknown; thus, further research is needed to understand the generalizability of the study findings.

In conclusion, UR is a disastrous and fatal event for obstetricians and patients. In order to reduce maternal and infant mortality, obstetricians should give enough attention to the pregnant women with high risk factors by strengthening the monitoring. TOLAC is a safe and worth promoting type of delivery for the patients, which still has a long way to go in Shanghai and China.

\section{Abbreviations}

Cl: Confidence intervals; ICU: Intensive-care unit; NICU: Neonatal intensivecare unit; OR: Odds ratios; TOLAC: Trial of labour after cesarean delivery; UR: Uterine rupture; VBAC: Vaginal birth after a caesarean section.

\section{Supplementary Information}

The online version contains supplementary material available at https://doi. org/10.1186/s12884-022-04415-6.

Additional file 1: Supplementary Table 1. Detailed descriptions of the three cases with uterine rupture of neonatal deaths.

\section{Acknowledgements}

We thank the study participants for permitting us to use their personal data.

\section{Authors' contributions}

SW and MY participated in interpretation of data and involved in drafting the manuscript. JP, XZ, YW and QS analyzed the data and critically revised the manuscript. CZ, GW and XH made substantial contributions to conception and design, interpreted the data, and critically revised the manuscript. All authors read and approved the final manuscript.

\section{Funding}

This research was supported by National Natural Science Foundation of China(81873816; 82071629); Foundation of Shanghai Municipal Health Commission (202040128) and Pudong Commission of Health and Family Planning (PW2019D-13).

\section{Availability of data and materials}

The datasets generated during and analyzed during the current study are not publicly available due to privacy concerns but are available from the corresponding author on reasonable request. Prospective scientists who are interested in are welcomed to contact the corresponding author via e-mail.

\section{Declarations}

\section{Ethics approval and consent to participate}

This study was approved by the Ethics Review Committee of Shanghai First Maternity and Infant Hospital, Tongji University School of Medicine (reference number: KS20268). We declare that all methods of this study were performed in accordance with the relevant guidelines and regulations (Declaration of Helsinki). Permission to access charts of mothers for retrieving data obtained from Shanghai First Maternity and Infant Hospital. Because the study was a retrospective chart review, the Ethics Review Committee of Shanghai First Maternity and Infant Hospital, Tongji University School of Medicine has waived the requirement of the informed consent for this study. However, confidentiality was maintained when handling each case files.

\section{Consent for publication}

Not required.

\section{Competing interests}

The authors declare that they have no competing interests.

Received: 25 May 2021 Accepted: 20 January 2022

Published online: 01 February 2022

\section{References}

1. Hofmeyr GJ, Say L, Gulmezoglu AM. WHO systematic review of maternal mortality and morbidity: the prevalence of uterine rupture. BJOG. 2005;112(9):1221-8.

2. Fox NS, Gerber RS, Mourad M, Saltzman DH, Klauser CK, Gupta S, et al. Pregnancy outcomes in patients with prior uterine rupture or dehiscence. Obstet Gynecol. 2014;123(4):785-9.

3. Ronel D, Wiznitzer A, Sergienko R, Zlotnik A, Sheiner E. Trends, risk factors and pregnancy outcome in women with uterine rupture. Arch Gynecol Obstet. 2012;285(2):317-21.

4. Rizwan N, Abbasi RM, Uddin SF. Uterine rupture, frequency of cases and fetomaternal outcome. J Pakistan Med Assoc. 2011;61(4):322-4.

5. Chauhan SP, Martin JN Jr, Henrichs CE, Morrison JC, Magann EF. Maternal and perinatal complications with uterine rupture in 142,075 patients who 
attempted vaginal birth after cesarean delivery: a review of the literature. Am J Obstet Gynecol. 2003;189(2):408-17.

6. Vilchez G, Hoyos LR, Maldonado MC, Lagos M, Kruger M, Bahado-Singh R. Risk of neonatal mortality according to gestational age after elective repeat cesarean delivery. Arch Gynecol Obstet. 2016;294(1):77-81.

7. Berhe Y, Wall LL. Uterine rupture in resource-poor countries. Obstet Gynecol Surv. 2014;69(11):695-707.

8. Motomura K, Ganchimeg T, Nagata C, Ota E, Vogel JP, Betran AP, et al. Incidence and outcomes of uterine rupture among women with prior caesarean section: WHO multicountry survey on maternal and newborn health. Sci Rep. 2017;7:44093.

9. Al-Zirqi I, Daltveit AK, Forsén L, Stray-Pedersen B, Vangen S. Risk factors for complete uterine rupture. Am J Obstet Gynecol. 2017;216(2):165.e161-8.

10. Practice Bulletin No. 183: Postpartum Hemorrhage. Obstet Gynecol. 2017;130(4):e168-86.

11. Markou GA, Muray JM, Poncelet C. Risk factors and symptoms associated with maternal and neonatal complications in women with uterine rupture. A 16 years multicentric experience. Eur J Obstet Gynecol Reprod Biol. 2017;217:126-30.

12. Lannon SMR, Guthrie KA, Vanderhoeven JP, Gammill HS. Uterine rupture risk after periviable cesarean delivery. Obstet Gynecol. 2015;125(5):1095-100.

13. Al-Zirqi I, Stray-Pedersen B, Forsen L, Daltveit AK, Vangen S. Uterine rupture: trends over 40 years. BJOG. 2016;123(5):780-7.

14. Vernekar M, Rajib R. Unscarred uterine rupture: a retrospective analysis. J Obstet Gynaecol India. 2016;66(Suppl 1):51-4.

15. Khanam RA, Khatun M. Ruptured uterus: an ongoing tragedy of motherhood. Bangladesh Med Res Counc Bull. 2001;27(2):43-7.

16. Guise JM, McDonagh MS, Osterweil P, Nygren P, Chan BK, Helfand M. Systematic review of the incidence and consequences of uterine rupture in women with previous caesarean section. BMJ (Clinical research ed). 2004:329(7456):19-25.

17. Astatikie G, Limenih MA, Kebede M. Maternal and fetal outcomes of uterine rupture and factors associated with maternal death secondary to uterine rupture. BMC Pregnancy Childbirth. 2017;17(1):117.

18. Sahin HG, Kolusari A, Yildizhan R, Kurdoglu M, Adali E, Kamaci M. Uterine rupture: a twelve-year clinical analysis. J Matern Fetal Neonatal Med. 2008;21(7):503-6.

19. Rouzi AA, Hawaswi AA, Aboalazm M, Hassanain F, Sindi O. Uterine rupture incidence, risk factors, and outcome. Saudi Med J. 2003;24(1):37-9.

20. Smith GC, White IR, Pell JP, Dobbie R. Predicting cesarean section and uterine rupture among women attempting vaginal birth after prior cesarean section. PLoS Med. 2005;2(9):e252.

21. Thisted DL, Mortensen LH, Krebs L. Uterine rupture without previous caesarean delivery: a population-based cohort study. Eur J Obstet Gynecol Reprod Biol. 2015;195:151-5.

22. Barber EL, Lundsberg LS, Belanger K, Pettker CM, Funai EF, Illuzzi JL. Indications contributing to the increasing cesarean delivery rate. Obstet Gynecol. 2011;118(1):29-38.

23. Denham SH, Humphrey T, deLabrusse C, Dougall N. Mode of birth after caesarean section: individual prediction scores using Scottish population data. BMC Pregnancy Childbirth. 2019;19(1):84.

24. Betrán AP, Ye J, Moller AB, Zhang J, Gülmezoglu AM, Torloni MR. The increasing trend in caesarean section rates: global, regional and National Estimates: 1990-2014. PLoS One. 2016;1 1(2):e0148343.

25. Wingert A, Johnson C, Featherstone R, Sebastianski M, Hartling L, Douglas Wilson R. Adjunct clinical interventions that influence vaginal birth after cesarean rates: systematic review. BMC Pregnancy Childbirth. 2018;18(1):452.

26. Dunsmoor-Su R, Sammel M, Stevens E, Peipert JL, Macones G. Impact of sociodemographic and hospital factors on attempts at vaginal birth after cesarean delivery. Obstet Gynecol. 2003;102(6):1358-65.

27. Mankuta DD, Leshno MM, Menasche MM, Brezis MM. Vaginal birth after cesarean section: trial of labor or repeat cesarean section? A decision analysis. Am J Obstet Gynecol. 2003;189(3):714-9.

28. Grobman WA, Peaceman AM, Socol ML. Cost-effectiveness of elective cesarean delivery after one prior low transverse cesarean. Obstet Gynecol. 2000;95(5):745-51.

29. McMahon MJ, Luther ER, Bowes WA Jr, Olshan AF. Comparison of a trial of labor with an elective second cesarean section. N Engl J Med. 1996;335(10):689-95.
30. Knight HE, Gurol-Urganci I, van der Meulen JH, Mahmood TA, Richmond $\mathrm{DH}$, Dougall A, et al. Vaginal birth after caesarean section: a cohort study investigating factors associated with its uptake and success. BJOG. 2014;121(2):183-92.

31. Al-Zirqi I, Stray-Pedersen B, Forsén L, Vangen S. Uterine rupture after previous caesarean section. BJOG. 2010;117(7):809-20.

32. Mu Y, Li X, Zhu J, Liu Z, Li M, Deng K, et al. Prior caesarean section and likelihood of vaginal birth, 2012-2016, China. Bull World Health Organ. 2018:96(8):548-57.

33. Martin JA, Hamilton BE, Osterman MJK. Births in the United States, 2018. NCHS Data Brief. 2019;346:1-8.

34. ACOG Practice Bulletin No. 205: vaginal birth after cesarean delivery. Obstet Gynecol. 2019;133(2):e110-27.

35. Osada H. Uterine adenomyosis and adenomyoma: the surgical approach. Fertil Steril. 2018;109(3):406-17.

36. Gil Y, Badeghiesh A, Suarthana E, Mansour F, Capmas P, Volodarsky-Perel A, et al. Risk of uterine rupture after myomectomy by laparoscopy or laparotomy. J Gynecol Obstetrics Hum Reprod. 2020;49(8):101843.

37. Cobellis L, Pecori E, Cobellis G. Comparison of intramural myomectomy scar after laparotomy or laparoscopy. Int J Gynaecol Obstet. 2004;84(1):87-8.

38. Parker WH, Einarsson J, Istre O, Dubuisson JB. Risk factors for uterine rupture after laparoscopic myomectomy. J Minim Invasive Gynecol. 2010;17(5):551-4

39. Koo YJ, Lee JK, Lee YK, Kwak DW, Lee IH, Lim KT, et al. Pregnancy outcomes and risk factors for uterine rupture after laparoscopic myomectomy: a single-center experience and literature review. J Minim Invasive Gynecol. 2015;22(6):1022-8.

40. Milazzo GN, Catalano A, Badia V, Mallozzi M, Caserta D. Myoma and myomectomy: poor evidence concern in pregnancy. J Obstet Gynaecol Res. 2017;43(12):1789-804.

41. Gibbins KJ, Weber T, Holmgren CM, Porter TF, Varner MW, Manuck TA. Maternal and fetal morbidity associated with uterine rupture of the unscarred uterus. Am J Obstet Gynecol. 2015;213(3):382.e381-6.

42. Vandenberghe $G$, De Blaere M, Van Leeuw V, Roelens K, Englert Y, Hanssens $\mathrm{M}$, et al. Nationwide population-based cohort study of uterine rupture in Belgium: results from the Belgian obstetric surveillance system. BMJ Open. 2016;6(5):e010415.

43. Vilchez G, Nazeer S, Kumar K, Warren M, Dai J, Sokol RJ. Contemporary epidemiology and novel predictors of uterine rupture: a nationwide population-based study. Arch Gynecol Obstet. 2017;296(5):869-75.

44. Leung AS, Leung EK, Paul RH. Uterine rupture after previous cesarean delivery: maternal and fetal consequences. Am J Obstet Gynecol. 1993;169(4):945-50.

45. Phelan JP. Uterine rupture. Clin Obstet Gynecol. 1990;33(3):432-7.

46. Cowan RK, Kinch RA, Ellis B, Anderson R. Trial of labor following cesarean delivery. Obstet Gynecol. 1994;83(6):933-6.

\section{Publisher's Note}

Springer Nature remains neutral with regard to jurisdictional claims in published maps and institutional affiliations. 